\title{
Poetry
}

\section{Invisibility and death}

You have to die a few times before you can really live. - Charles Bukowski

My first death was in June 2007. She took her last breath, she turned grey and cold and I died with her. I was invisible before everyone.

Then, slowly — I returned.

My second death was in May 2010. I was doing my obstetrics rotation. "You're worthless", they said. "You're below expectations". "Flat affect - poor interactions with patients." No lunch, just shoulder dystocia. Loving my patients but hating my attendings. Hating being there at all. Standing in ORs - not understanding anything. Not knowing. Being pimped and never having the answer. Shocked, angry stares.

I turned cold and grey. I now believed what they had been pushing on me since the beginning of medical school - I was invisible. I convinced myself and faded into the walls once more.

My third death - my invisibility act, was in December 2011. The man I had loved for four years had sucked everything out of me - I could no longer cater to him. Medical school had sucked it all out of me already.

Grey, cold - just like her hands.

No one could ever want a corpse bride. Men want a red-cheeked woman with blood in her veins. I've been drained, filled with formaldehyde. I'm a cadaver now I'm back in 1st-year medical school. I'm haunting the nightmares of 21-year-old girls participating in the rites of medicine for the first time. I'm waking in the night in the anatomy lab morgue. I'm looking for you.

\section{Holly Delaney}

MD candidate 2013

University of Toronto

Toronto, Ont

Editor's note: This poem won honourable mention in the "Best Student Work" category of the Ars Medica and CMAJ Humanities Poetry and Prose Contest.

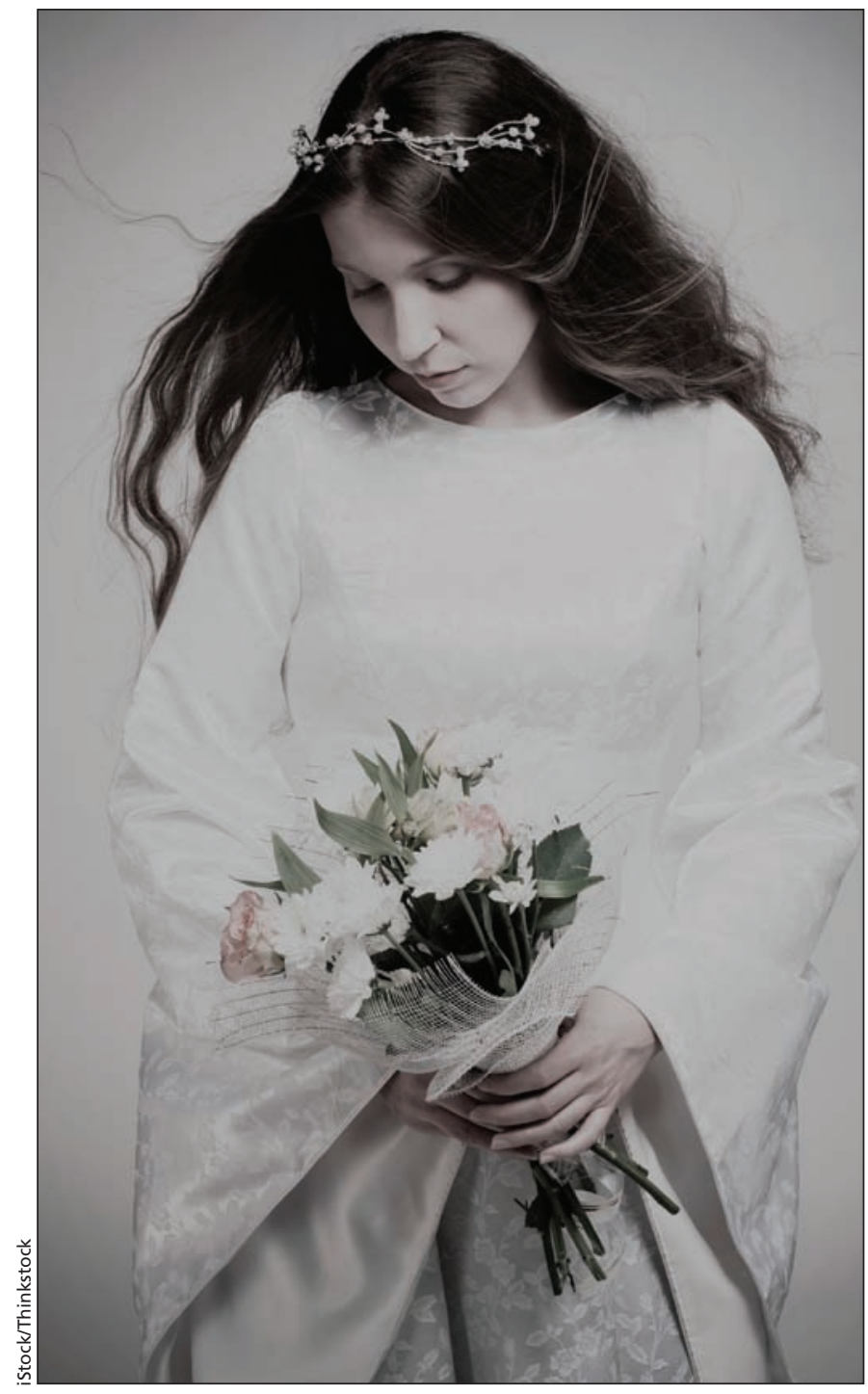

CMAJ 2014. DOI:10.1503/cmaj.130836 